\title{
AS CAPAS DOS LIVROS DE ARTISTA DE AL BERTO: COMENTÁRIOS
}

Gustavo Cerqueira

Guimarães*

RESUMO: Este ensaio crítico pretende explorar as publicações marginais do poeta lusitano Al Berto a partir de Trabalhos do olhar (1982), momento em que é inaugurada uma nova fase olhar (1982), momento em que é inaugurada uma nova fase do escritor ao se inserir definitivamente no mercado editorial de Portugal. Para tanto, realiza-se um breve percurso do poeta capas, alijadas da obra completa $O$ medo (1987), das primeiras edições das obras $O$ último habitante (1983), A seguir o deserto (1984), O livro dos regressos (1989), Canto do amigo morto (1991) e Luminoso afogado (1995), seguidas dos comentários de alguns dos principais críticos do poeta.

Palavras-chave: Al Berto; paratexto; literatura e fotografia; literatura portuguesa contemporânea.

gustavocguimaraes@hotmail.com

Doutor em Estudos Literários pela UFMG / PNPD-Capes.

ABSTRACT: This critical essay aims to explore the marginal publications of the Portuguese poet Al Berto from Trabalhos do olhar (1982), when it is inaugurated a new phase of the writer is definitely enter the publishing of Portugal. The study presents a brief poet's journey to better situate it in its literary context, we present the covers, pushed out the complete works $O$ medo (1987), the first editions of works $O$ último habitante (1983), $A$ seguir o deserto (1984), O livro dos regressos (1989), Canto do amigo morto (1991) and Luminoso afogado (1995), followed by comments from some of the leading critics of the poet.

Keywords: Al Berto; paratext; literature and photography; Portuguese contemporary literature. 
1. Trabalhos do olhar, Lisboa: Contexto, nov. 1982.

\section{ANOS 1980: AGORA SOU PROFISSIONAL?}

Um livro é produzido, evento minúsculo, pequeno objeto manejável. A partir daí, é aprisionado num jogo contínuo de repetições; seus duplos, a sua volta e bem longe dele, formigam; cad leitura atribui-lhe, por um momento, um corpo impalpável e único; fragmentos de si próprio circulam como sendo sua totalidade, passando por conte-lo quase todo e nos quais acontece-lhe, finalmente, encontrar abrigo; os comentários desdobram-no, outros discursos no qual enfim ele mesmo deve aparecer, confessar o que se recusou a dizer, libeta-se daquilo que, ruidosamente, fingia ser. A reedição numa outra época, hunn outro lugar, ainda é um desses duplos: nem um completo engodo, nem uma completa identidade consigo mesmo.

Michel Foucault, História da loucura.

No início da década de 1980, o poeta Al Berto (19481997) publicou o seu sétimo livro, Trabalhos do olhar (1982), o primeiro por uma editora regida pela norma padrão de publicação e circulação de obras. O lançamento foi pela Contexto, editora lisboeta de maior destaque ao longo dos quinze anos da trajetória literária de $\mathrm{Al}$ Berto pelo mercado editorial, cujos livros foram editados desde o marco Trabalhos do olhar até a sua última publicação em vida, o derradeiro Horto de incêndio (Assírio \& Alvim: Lisboa, 1997), um sucesso de vendagem devido, entre outros fatores, à sua morte aos quarenta e oito anos, em uma sexta-feira 13 noite de junho na capital portuguesa.
Os amigos que o levaram ao Cemitério dos Prazeres [...] em ritual de despedida pela definitiva ausência, veriam, à volta, nas vitrines das livrarias, mais um rastro de sua perene presença. Impresso em capa negra, este inventário do fim irremediável apresenta uma tarja, da mesma cor, cobrindo a lombada. Rompendo o indiferenciado do negro da capa, o rosto de Al Berto coberto pelas mãos, fotografado em 1990 por Paulo Nozolino, deixa visível um olho granítico, áspero. Justo o olhar cortante, entre o sonho e a realidade, cuja importância em sua poética é epigrafada desde Trabalhos do olhar. $^{2}$

Esse livro é composto por quarenta e nove poemas escritos entre 1976 e 1982, divididos em sete séries: "Mar-de-leva" (anteriormente publicado como plaquete), "Dispersos de Milfontes", "Alguns truques de ilusionismo", "Sete dos ofícios", "Tentativas para um regresso à terra", "Filmagens" e "Trabalhos do olhar". Esta última série, constituída por doze poemas, havia sido publicada separadamente meses antes, em pequena tiragem rapidamente esgotada - Trabalhos do olhar (1982). ${ }^{3}$

Esses "trabalhos do olhar" e a transformação do texto de Al Berto ocorrem em consequência de seu regresso para Sines, cidade marítima do Alentejo, e, igualmente, deve-se muito ao seu reencontro com a literatura portuguesa a partir de seu retorno do exílio em 1975, como ele mesmo atesta
2. PEREIRA. Portugal - poetas do fim do milênio, p. 136. 
em entrevista ao programa dedicado à sua obra exibido pela emissora RTP, no qual é destacada a importância do "poeta-fotógrafo" Cesário Verde:

Eu penso que o mais fascinante pra mim foi reler toda a poesia portuguesa com uma espécie de disponibilidade que eu não tinha tido e com uma distância muito grande em relação a isso Há poetas que eu fiquei absolutamente aturdido. Foi como se tivessem me dado uma marretada na cabeca e dissessem assim: - grandessíssimo idiota, como é que não tinha lido isto?! [...] E aí de fato há nomes. Há nomes e dos mais variados: o Antero [de Quental, 1842-1891], o Camilo Pessanha [1867-1926]. O Cesário [Verde, 1855-1886] pra mim é importantíssimo. É um poeta fotógrafo. Ele é fotográfico. Há fascínio pela fotografia quando releio o Cesário. Há de fato qualquer coisa de empatia com aquilo tudo e com a cidade, embora o meu olhar sobre a cidade seja outro, seja muito mais noturno do que propriamente diurno [...]. O Eugênio [de Andrade, 1923-2005] pra mim é uma descoberta a certa altura. A Sofia [de Melo Breyner, 1919-2004], o lado cristalino e límpido da Sofia é uma coisa que me deixa quase sem fôlego. Achava aquilo tudo de uma imensa beleza [...]. Ruy Belo [1933-1978] é importantíssimo, eu conhecia mal o Ruy Belo. Quando se reeditam as suas obras completas é pra mim uma novidade, é um poeta que eu descubro e que não tinha notícia de se poder escrever assim em português. É esse o meu espanto. E muito mais na poesia do que na prosa. ${ }^{4}$
Nesta altura, há uma mudança radical na poética de $\mathrm{Al}$ Berto, a princípio na forma, pois a partir de Trabalhos do olhar a escrita do autor é caracterizada por poemas que não ultrapassam uma página, em oposição às longas e vertiginosas escritas predominantes das primeiras publicações, onde figuram muitos personagens misturados ao lirismo do sujeito que se enuncia por meio de uma forma limítrofe entre a prosa e a poesia. O título Trabalhos do olhar é emblemático e lança compreensão à toda obra, pautada pela relação entre reminiscências e figurações, como se nota nos versos finais do poema "5" da série "Filmagens":

a memória poderá reconstruir tudo a partir das imagens e do intenso cheiro a mato

por agora nada mais é visíve

azul e mais azul e nenhuma mudança na paisagem nenhum vestígio

as luzes apagaram-se o material foi guardado

o lugar adormece por baixo do bolor imutável

e no esquecimento

os actores caminham para of im do filme

um gravador esquecido

regista os passos que se afastam devagar

não sabemos ao certo para onde.
5. AL BERTO. Trabalhos do olhar. $O$ medo, p. 205 (grifos meus) 
6. AL BERTO. Trabalhos do olhar. $O$ medo, p. 219.

7. AL BERTO. Uma existência de papel. $O$ medo, p. 542

8. O medo - trabalho poético 1974 1986. Lisboa: Contexto, 1987. Encenação caravaggiana de A Berto na capa.
Não só a forma mudou nas composições de Al Berto, pois a categoria "tempo", como se nota, toma proporções estimulantes a partir do constante registro sobre o apagamento do sujeito, acrescidos, embora com menor frequência, da dimensão futura, evidenciada quer em meio às especulações da voz que se enuncia quase sempre em primeira pessoa - "que horas serão para lá desta fotografia?”6 - quer em meio a algumas remissões a oráculos, deuses, sábios e nômades, seguindo certa tradição francófona por meio de seu diálogo explícito com Rimbaud, a exemplo do trecho do poema a seguir, presente em Uma existência de papel (Porto: Gota d'Água, 1985): "a partir de hoje abandono-te para sempre / ao silêncio de quem escreve versos / em Portugal / tens trinta e sete ano como Rimbaud / talvez seja tempo de começares a morrer". Temas também presentes em Salsugem (1984) e Três cartas da memória das Índias (1985), ambos editados pela Contexto.

A partir da segunda metade dos anos 1980, Al Berto fre quenta mais a capital portuguesa e troca definitivamente

Sines por Lisboa, onde se radica a partir de janeiro de 1987. É o ano da consagração: volume de obra completa [ $O$ medo 1987], ${ }^{8}$ prêmio do PEN Clube [1988], eco midiático consequente. Nele, reúnem-se todos os livros, exceto o Projets 69, a maioria dos poemas publicados em revistas, poucos textos dispersos em francês, folhas volantes, plaquetes, e, a grande novidade, os inéditos escritos em forma de diário, subdivididos em "O medo (1)", “O medo (2)" e "O medo (3)”. Faz então o trajeto do autor que acedeu ao pátio da fama. ${ }^{9}$

Nessa altura, o PEN Clube Português estava sob os cuidados dos escritores Vasco Graça Moura, Pedro Tamen e E. M. de Melo e Castro, que registrou sua opinião em recensão crítica à época:

a publicação de $O$ medo [...] veio confirmar $\mathrm{Al}$ Berto como um dos poetas mais legíveis do final dos anos 70 e da década de 80. Legível não no sentido da facilidade proporcionada pelo encontro das fórmulas já conhecidas, mas sim, precisamente, legível pelo prazer de reencontrar um discurso capaz de nos surpreender e emocionar com a intensidade das descobertas. ${ }^{10}$

O reconhecimento do grande público veio a partir dessa publicação, quando Al Berto se consolidou definitivamente no mercado editorial, com êxito de vendas e boa recepção entre os críticos e os leitores, inclusive fora de Portugal, pois foi traduzido para o francês, alemão, inglês, espanhol e italiano Porém o poeta não deixou de lado as suas publicações marginais, dando continuidade à edição de seus próprios textos iniciada em Bruxelas em 1972 por meio de Projectos 69, seu primeiro livro de artista. ${ }^{11}$
9. PITTA. Metal fundente, p. 12 .

10. MELO E CASTRO Colóquio-Letras, p. 104.

11. Na visão de Maria do Carmo Veneroso, importante pesquisadora do tema no Brasil, "o livro de artista será compreendido como obra intermidiática, já que pela sua própria natureza híbrida e mutante, ele está situado, frequentemente, na interseção entre diferentes mídias. Impressão, escrita, fotografia, design gráfico, entre outras coisas, convivem num espaço no qual não cabem definições fechadas, já que o livro de artista é múltiplo, possibilitando assim diversas formas de

aproximação". Cf.: VENEROSO Palavras e imagens em livros $d$ artistas, Pós, 2012, p. 82-103. 
12. Cf. FREITAS. A noite dos espelhos; e FREITAS. Me, Myself and I.
No entanto, todas as fotografias publicadas por Al Berto em seus livros foram alijadas do tomo $O$ medo; porém não é novidade alguma atentar para a importância de lê-las, visto que estão presentes no corpo do texto ou em praticamente todas as capas de seus livros. Assim, este ensaio vai em direção ao que o próprio poeta sempre nos sensibilizou a perceber: a fotografia e o cuidado ao criar as capas de seu livros (além de todos os elementos paratextuais), tornando-se potentes objetos de leitura, pois especialmente em Al Berto, há concordância entre vários críticos de que as imagens devem ser tratadas como parte fundamental de compreensão de sua obra. ${ }^{12}$

\section{OS LIVROS DE ARTISTA ÀS MARGENS DE PUBLICAÇÃO (1983-1995)}

Os livros são objetos transcendentes Mas podemos amá-los do amor táctil

Que votamos aos maços de cigarro Domá-los, cultivá-los em aquários, Em estantes, gaiolas, em fogueiras Ou lançá-los pra fora das janelas ( Talvez isso nos livre de lançarmo-nos) $\mathrm{Ou}$ - o que é muito pior - por odiarmo-los Podemos simplesmente escrever um.

Caetano Veloso, Livro.
$\mathrm{O}$ fato de $\mathrm{Al}$ Berto ter entrado para o mercado editorial não o fez um poeta voltado apenas para essa prática de publicação, pois ele nunca abandonou a feitura de seus livros de artista nem as práticas marginais, mantendo o fluxo lateral de suas edições performativas não convencionais de circulação por meio das seguintes obras: O último habitante (1983), A seguir o deserto (1984), O livro dos regressos (1989), Canto do amigo morto (1991) e Luminoso afogado (1995). ${ }^{13}$

As plaquetes com o destacado poema $O$ último habitante (1983), ${ }^{14}$ em tiragem de duzentos exemplares, e $A$ seguir o deserto (1984), ${ }^{15}$ com cerca de 20 páginas, numa tiragem de quinhentos exemplares, foram concebidas na Rua do Forte, em Sines. Essas publicações ficaram a cargo da editora lisboeta Frenesi e a montagem a cargo de Paulo da Costa Domingos, que segundo o crítico Manuel de Freitas é "um dos mais inventivos editores europeus", ${ }^{16}$ sobretudo nas décadas de 1980 e 1990, também com uma vasta produção poética.

"O último habitante" é o único poema com o status de divulgação singularizada durante os anos de publicação do autor. O texto de duas páginas de média espessura, de cor gris, apresenta-se revestido por uma capa espessa de cor negra, com um pequeno furo circular ao centro por onde se vê a imagem de um homem com uma mala à mão - posteriormente o poema foi integrado à obra completa $O$ medo. Ao abrir a capa da plaquete, vê-se na página de rosto a fotografia
13. Vejam-se ainda as plaquetes $\mathrm{e}$ os livros de artista editados por Al Berto no período de 1972 a 1982: Projets 69 (Bruxelas: 1972); À procura do vento num jardim d'agosto (Lisboa, 1977); Meu fruto de morder todas as horas (Lisboa: 1980); Mar-de-leva (Sines: 1980); Dix adresses avant de disparaitre (Montreal: 1981); e, Trabalhos do olhar (Sines: 1982). Esta disposição das obras se diferencia da maneira encontrada em 0 medo (trabalho poetico 1974-1997), que apresenta os livros pela datação de sua

escrita, e não de sua publicação, além de não trazer as duas obras publicadas fora de Portugal. Para maior aprofundamento sobre a primeira década de publicação de Al Berto, veja o estudo de minha autoria, "Al Berto, poeta-editor: as margens da poesia" (2015) publicado na revista Estudos

14. O último habitante. Lisboa: fotografia de Paulo Nozolino.

15. A seguir o deserto. Lisboa: Frenesi, ago. 1984. Fotografia de Paulo Nozolino.

16. FREITAS. Expresso, Lisboa, 15 ago. 2009. 
17. O fotógrafo Paulo Nozolino é um porán maioria das encenações

fotográficas de Al Berto em seus

livros. O diálogo entre eles se

dá em cinco ocasiões: $O$ último

habitante, Salsugem, A seguir

o deserto, $O$ medo e Horto do

incêndio.

18. Al Berto. $O$ último habitante. $O$ medo, p. 239 de um homem solitário a caminhar em uma estrada de terra em direção à praia, ao mar, retratada por Paulo Nozolino. ${ }^{17}$ A imagem traz "o último habitante do lado mitológico das cidades", ${ }^{18}$ que tanto urge a obra al-bertiana.

Já em A seguir o deserto, confere-se na larga orelha da capa a fotografia, também de Nozolino, de um homem sem identificação a exibir parte de suas coxas e seu pênis em ereção. Para Manuel de Freitas, "supõe-se o corpo de
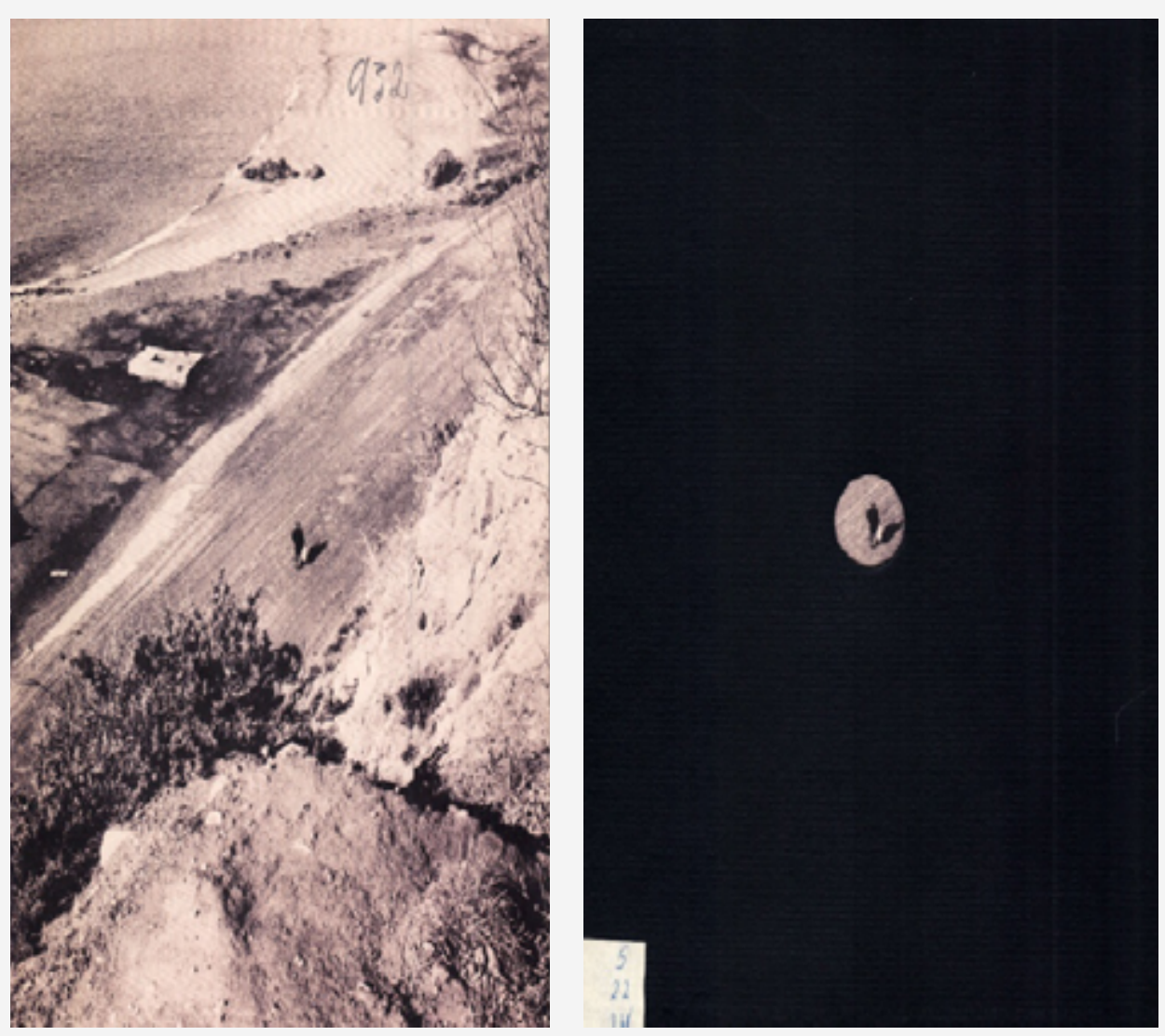

Al Berto". ${ }^{19}$ Esta imagem é consoante às imagens eróticas e lisérgicas recorrentes na escrita de Al Berto. O livro que anuncia "o deserto" traz logo ao abri-lo a surpreendente imagem do órgão genital masculino ereto com um lençol branco ao fundo, além de muitas referências no texto ao próprio sexo, ao desejo e à noite, à escrita e à melancolia Esses temas invariavelmente estão associados a espaços de difícil cifragem pelo homem, como os espaços especulares, desérticos e marítimos, ${ }^{20}$ sugerindo o entrelaçamento de todas essas instâncias, o que gera uma constante perturbação do sujeito:

ainda entesado olho-me no espelho a noite envolve as enxárcias húmidas deste navio-cama odores mornos de urina

$[\ldots]$

levanto-me e pela janela apercebo o mar

amanhece

como sempre acontece assim que pressinto o mar

tenho a cara manchada de sal

um gemido sobe cola-se ao espelho à pele do rosto

grito. $^{21}$
19. Freitas. Me, Myself and I, p. 56

20. Cf.: DELEUZE; GUATTARI. O liso o estriado. Mil platôs, vol. 5, p. 179214. Segundo os autores, o mar é o arquétipo do espaço liso em oposição ao espaço estriado. “É no mar que pela primeira vez o espaço liso foi domado, e se encontro um modelo de ordenação, de outros lugares" (p. 186-7), coma outros lugares" (p. 186-7), como

1. Al Berto. A seguir o deserto. $O$ medo, p. 343 


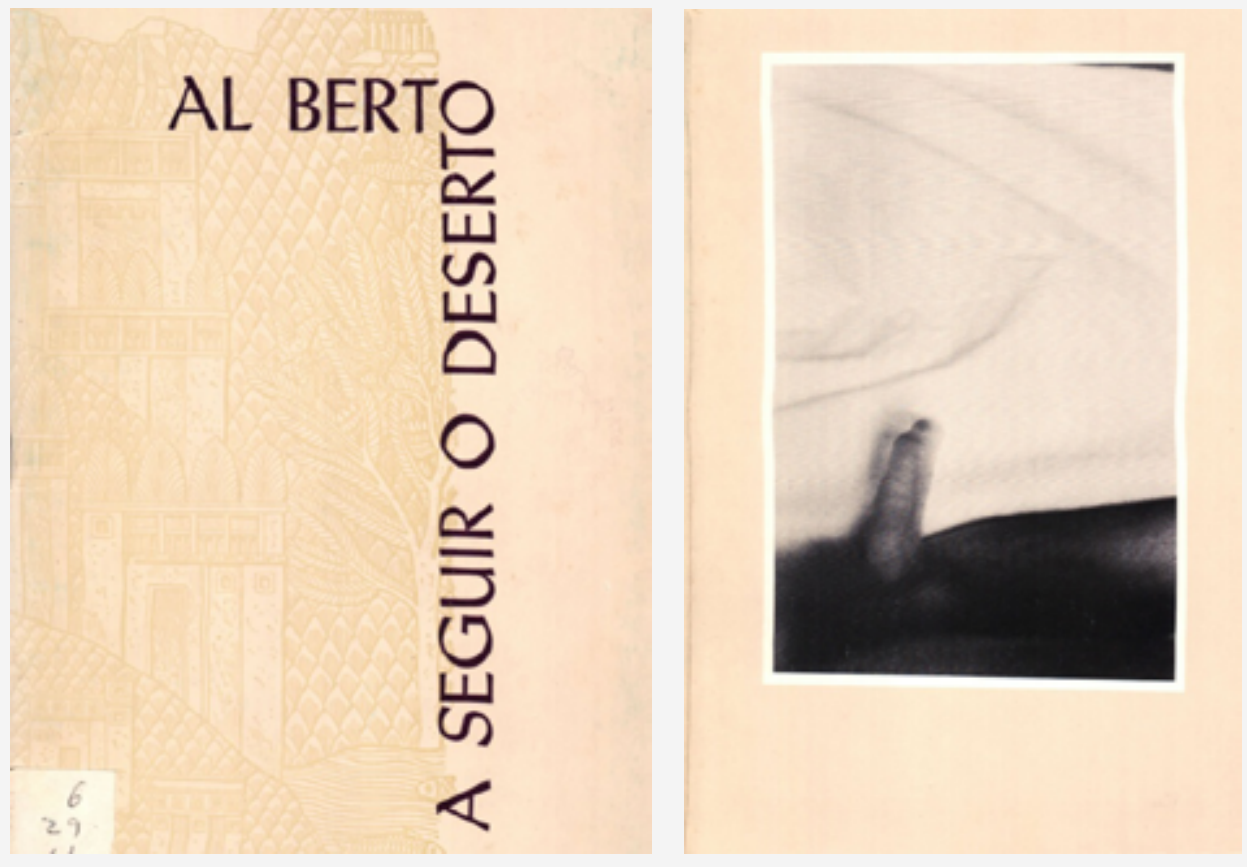

Em $A$ seguir o deserto, observa-se o espaço referido no título se fundindo ao nome do autor, sugerindo indistintas analogias entre as instâncias do sujeito que se enuncia e o espaço onde ele transita. Essa superposição logo no título já indica as inúmeras imagens de indistinção entre o "eu" e o "espaço" (ou o outro) existentes na obra:

tocava-te e reconhecia-me

afinal não existia diferença entre o meu corpo e o seu reflexo chamaram a esta coincidência loucura

será mesmo Lisboa? ${ }^{22}$
Fernando Pinto do Amaral nos propõe pensar a obra de Al Berto situada entre dois polos: o "excesso e a vertigem do sentir" e "o deserto e a lucidez da distância e da solidão [...]. De início mais entregue ao primeiro, atingiu depois um grau de maturidade e depuração que culmina, a meu ver, n'Uma Existência de Papel (1985)”. ${ }^{23}$ Para Eduardo Prado Coelho, um dos mais importantes críticos portugueses da segunda metade do século XX, o mais expressivo nesse trabalho de Al Berto

e modo como ele vai traçando o frágil rendilhado negro desta impregnação da morte. Ela começa na fotografia que acompanha o volume [na folha de rosto] e reduz a imagem da mão ao seu recorte sombreado. Ela passa pelo título,

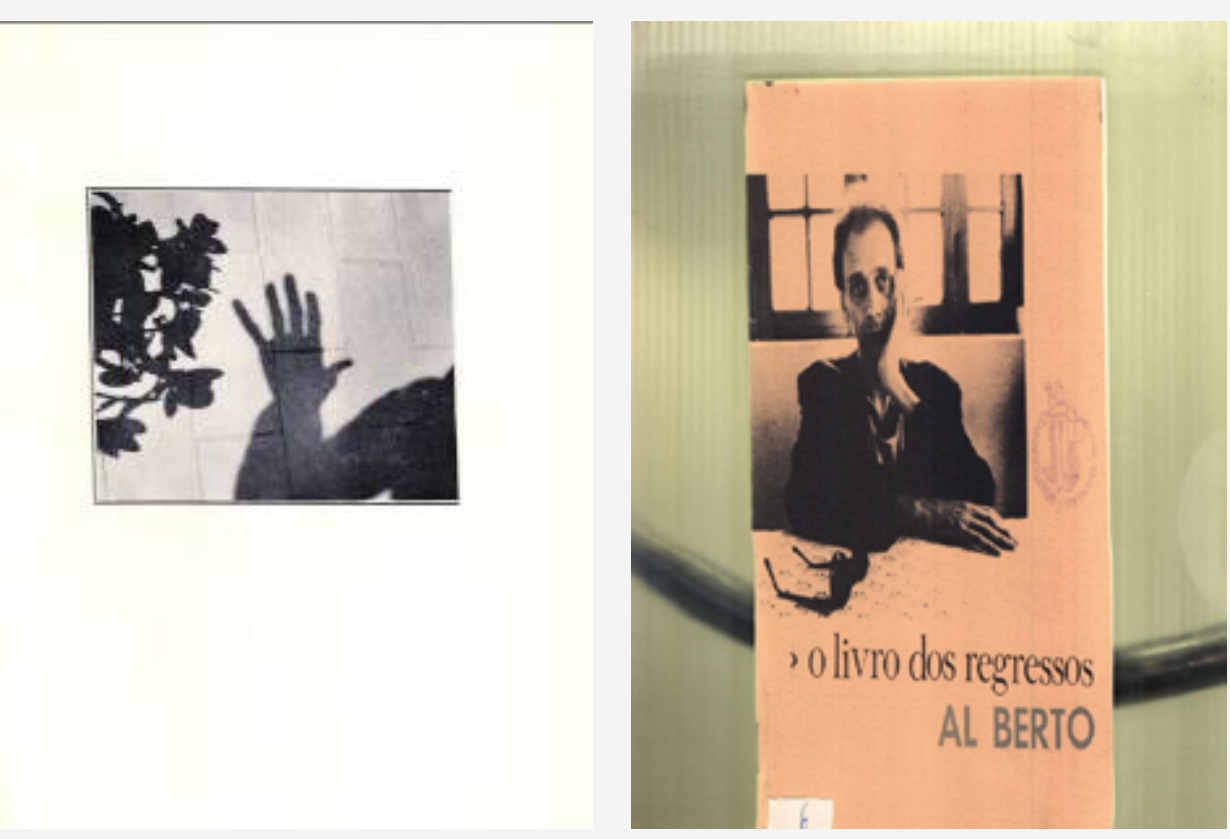

23. Amaral. Al Berto: um lirismo do excesso e da melancolia, p. 121
EM TESE

BELO HORIZONTE

v. 22

N. 3

SET.-DEZ. 2016

GUIMARÃES. As capas dos livros de artista de Al Berto: comentários

P. $34-44$ 
24. Coelho. Al Berto: começar a morrer, p. 156.

25. O livro dos regressos. Lisboa: frenesi, set. 1989; $2^{\mathrm{a}}$ tiragem: nov. 1989. Encenação fotográfica de Al Berto. Capa de Helder Lage; vinheta sobre fóssil de hipocampo e layout de pcd (Paulo da Costa Domingos).

26. Cf. O livro dos regressos. $O$ medo, p. 547-73. onde esse diz o modo como a existência se vai desmunindo e adelgaçando até ficar reduzida à leveza evanescente de um papel. ${ }^{24}$

Em 1989 é publicado O livro dos regressos, ${ }^{25}$ em tiragem de quinhentos exemplares, pela Frenesi, editora cuja participação é de destaque ao lançar muitos poetas desde 1979 aos dias de hoje. O livreto de trinta e duas páginas traz encenação fotográfica de Al Berto na capa. O texto se enuncia entrecortado, como se fossem dois poemas. Porém, as últimas sete páginas se desenvolvem sem alternância. Ou seja, um dos poemas tem duração maior. Esse formato lembra o método cut-up burroughsiano, igualmente empregado em Meu fruto de morder todas as horas. Para marcar a alternância de vozes, usa-se o negrito distinguindo-se cada uma delas, características também desse método, bem como as mudanças do estilo, da fonte e/ou do tamanho das letras. ${ }^{26}$

Pitta publicou uma recensão crítica sobre O livro dos regressos no ano de seu lançamento, na qual o crítico especula sobre a possibilidade de $\mathrm{Al}$ Berto realizar uma espécie de "balanço" de seu processo de escrita ligado ao seu percurso até aqui:

regressa para onde nunca estiveste

reconstrói em ti a pequena ruína dos brinquedos

no quarto escuro refaz o fugitivo corpo da rumorosa existência de papel bebe

a ansiedade venenosa das palavras o sangue

das perdidas aves no surdo coração da viagem. ${ }^{27}$

Nos anos 1990 começa a se destacar na obra de Al Berto uma grande desolação no decorrer dos textos que intentam a impossível tarefa de caminhar para o seu próprio apagamento, para o seu silêncio. Uma poesia que anseia a imobilidade, que se quer mineralizada, como bem sintetizada na fotografia da pedra de Paulo da Costa Domingos presente na capa de Canto do amigo morto.

Há nesse texto, como em toda a obra, a exploração da matéria humana em seu devir-mineral - "sem mim, a pouco e pouco, transformar-te-ás em corpo mineral" ${ }^{28}$ - e vegetal

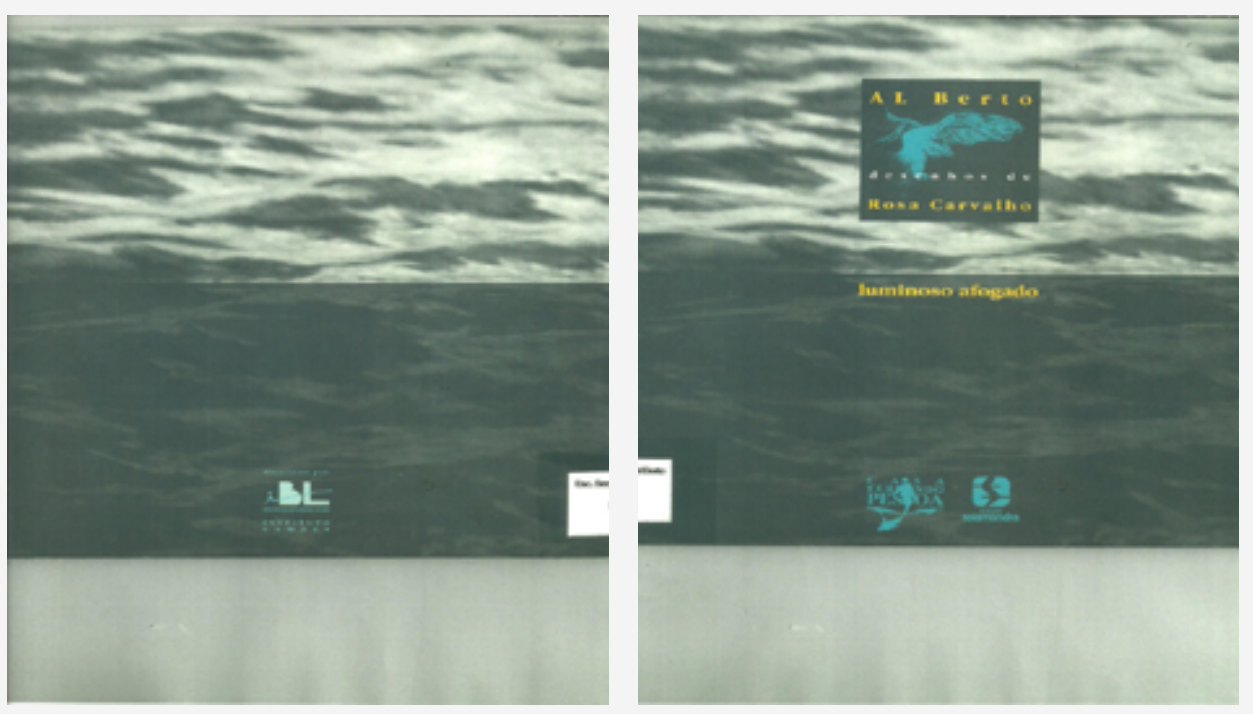

27. Al Berto. O livro dos regressos. $O$ medo, p. 555 .

28. Al Berto. Canto do amigo morto. $O$ anjo mudo, p. 91.
EM TESE v. 22

N. 3 
29. Al Berto. Canto do amigo morto. $O$ anjo mudo, p. 90.

30. Al Berto. Canto do amigo morto. $O$ anjo mudo, p. 90.

31. Al Berto. Canto do amigo morto. $O$ anjo mudo, p. 93.

32. Luminoso afogado. Lisboa: Casa Fernando Pessoa; Ed. Salamandra, 1995. Desenhos de Rosa Carvalho. Esse livro integra a obra $O$ medo a partir da terceira edição, em 1997.

33. Vasconcelos. Mundo-Arte: o rastro do novo, o dado do fim, p. 216.
- "o meu corpo é agora húmus e ausência"29 -, construídos por meio de um léxico carregado de ecos românticos infrequentes naquele final do século XX - "O tempo passa como cinza branda sobre os cabelos, aprisionando-os numa velhice futura - sem fim. Em meus ossos a terra iniciou o seu trabalho, lento, devorador. $\mathrm{O}$ ar corrompe-se na dor dos fogos-fátuos" ${ }^{30}$ Esse texto-canto caminha invariavelmente ao lado das temáticas do amigo, medo, melancolia, doença, peste e morte. É ponto nevrálgico o embate do sujeito enunciando a ausência-presença do amado amigo: "O último deserto que me resta de ti é a noite da escrita. Nela te mantenho vivo, amante morto [...]. Vivo para a travessia do corpo que me sepultou na memória... o teu". ${ }^{31}$

Por fim, a última publicação de Al Berto faz eco consequente em Luminoso afogado (1995), ${ }^{32}$ livreto com tratamento distinto produzido pela Casa Fernando Pessoa por meio do projeto "Ciclo um Poeta e um Pintor", que contaria com texto de Al Berto seguido de desenhos a carvão de Rosa Carvalho. Os embates entre o eu e o outro, entre morte e vida, escrita e silêncio, memória e apagamento e real e fictício tangenciam todo o texto agonicamente, levados à exasperação do sujeito. Maurício Vasconcelos diz que esse livro é "um dos escritos mais trabalhados nesse fim, e fio, de vida: jogo modulativo da palavra enquanto fala, entre o desastre (vindo das extensões, do mar, do mar português) e o rastro do luminoso". ${ }^{33}$
Assim, vistos por este ângulo, esses elementos já se apresentam anteriormente na capa por meio do título, afogado / luminoso, e da imagem de dois dos espaços mitológicos e de difícil cifragem para o Homem: a vastidão do céu, luminoso, em contraste com o mar, onde se dá o naufrágio do corpo - "o país líquido que habitámos". ${ }^{34}$ Contudo, ao mesmo tempo, a imagem sugere a fusão desses lugares por meio da constituição da aposição: céu-mar.

Al Berto é possuidor de um projeto literário que inclui a vida, o corpo, e a morte sempre tencionados. O papel da escrita parece nele funcionar como um lugar para se eternizar o corpo por meio da estetização de si, da sua existência. "Com efeito, ao tradicional desregramento sucede agora um discurso (perceptível a partir da publicação, em 1985, de Uma existência de papel) que não anda longe de uma séria tentativa de contensão, capaz de se rever na 'difícil arte da melancolia”'. ${ }^{35}$ Importante salientar que a melancolia nessa altura passa a ser um dos operadores teóricos mais articuláveis à obra de Al Berto. O ensaio "Al Berto: um lirismo do excesso e da melancolia” (1991), de Fernando Pinto do Amaral, poeta e professor da Universidade Nova de Lisboa, é um dos mais bem acabados sobre o poeta. "O mundo de Al Berto pode considerar-se, [...] um dos mais melancólicos da nossa poesia recente [...], essa sensação psico-afetiva herdeira da acedia medieval e em que se conjugam, saturnianamente e numa
34. Al Berto. Luminoso afogado. $O$ medo, p. 590.
BELO HORIZONTE

v. 22

N. 3

SET.-DEZ. 2016

GUIMARÃES. As capas dos livros de artista de Al Berto: comentários

P. $34-44$ 
36. Amaral. O mosaico fluido, p. 125. Esse livro foi escrito em 1991 foi vencedor no ano seguinte do Prêmio Pen Clube, categoria Ensaio. Os textos crítico e poorico săo dedicados à literatura portuguesa. indefinível mistura, o torpor, a nostalgia e o tédio". ${ }^{36}$ Esses fatores, entretanto, configuram-se constantemente em meio à luminescência e à velocidade.

Hoje, Al Berto é publicado pela Assírio \& Alvim, que pertence ao Grupo Porto Editora. E nos mostrou durante o seu percurso literário que é possível levar a cabo paralelamente o seu projeto estético-político sem se deixar levar pelas imposições do mercado editorial. Ou seja, é possível ser um poeta reconhecido pela crítica e público, com boa vendagem de livros, e ao mesmo tempo não perder a autonomia de suas publicações, mantendo o seu caráter de urgência, como dizia. Dessa forma, Al Berto é um exemplo de resistência ao mostrar que em meio ao paulatino crescimento do mercado editorial em Portugal, sempre optou por não abandonar seu projeto de publicação de livros de artista, hoje, novamente tão em voga.

\section{REFERÊNCIAS}

Al Berto. Trabalhos do olhar. Sines: Edição do Autor, 1982. Fotografia da capa de António C. Pidwell Tavares.

Al Berto. Trabalhos do olhar. Lisboa: Contexto, 1982. Edição aumentada.

Al Berto. O último habitante. Lisboa: Frenesi, 1983. Fotografia de Paulo Nozolino.
Al Berto. A seguir o deserto. Lisboa: Frenesi, 1984. Fotografia de Paulo Nozolino.

Al Berto. Uma existência de papel. Porto: Gota d'Água, 1985. Fotografia do autor

Al Berto. O livro dos regressos. Capa de Helder Lage; vinheta sobre fóssil de hipocampo, e layout de pcd. Lisboa: Frenesi, 1989.

AL BERTO. Canto do amigo morto. Desenhos de José Pedro Croft; capa, layout e supervisão gráfica de Paulo da Costa

Domingos. Inclui tradução francesa de Natália Coelho. Lisboa: Europália, 1991

AL BERTO. O anjo mudo. Lisboa: Assírio \& Alvim, 2000 [1993].

AL BERTO. Luminoso afogado. Desenhos de Rosa Carvalho: imagem gráfica de Susana Francisco e Jorge António; fotografia de Al Berto por Adriana Freire. Lisboa: Casa Fernando Pessoa: Edições Salamandra, 1995

AL BERTO. Horto de incêndio. Na capa: Al Berto, Lisboa, 1990 fotografia de Paulo Nozolino. 3. ed. Lisboa: Assírio \& Alvim, 2000 [1997].

AL BERTO O medo - trabalho poético 1974-1997. 3. ed., rev. e aum. Fotografia do autor em homenagem a Caravaggio por Paulo Nozolino. Lisboa: Assírio \& Alvim, 2005.

AL BERTO. Entrevista à RTP (rede televisiva). Disponível em: $<$ http://www.youtube.com/watch? $v=$ eywxQ80EdfA $>$. Acesso em 5 ago. 2016. 
AMARAL, Fernando Pinto do. Al Berto: um lirismo do excesso e da melancolia. In: mosaico fluido. Lisb Alvim, 1991. p. 119-30.

COELHO, Eduardo Prado. Al Berto: começar a morrer. In: A noite do mundo. Lisboa: Imprensa Nacional Casa da Moeda 1988. p. 156-157.

DELEUZE, Gilles; GUATTARI, Félix. O liso e o estriado. In: Mil platôs, capitalismo e esquizofrenia.Trad. Peter Pál Pelbart. São Paulo: Editora 34, 2002. v. 5. p. 179-214.

FREITAS, Manuel de. A noite dos espelhos: modelos e desvios culturais na poesia de Al Berto. Lisboa: Frenesi, 1999

FREITAS, Manuel de. Me, Myself and I: autobiografia e

imobilidade na poesia de Al Berto. Lisboa: Assírio \& Alvim, 2005.

Freitas. Memórias de um editor. Expresso, Lisboa, 15 ago. 2009. Disponível em: <http://expresso.sapo.pt/critica-de-livros-de-15-a21 -de-agosto $=f 530391>$. Acesso em: 25 abr. 2016

GUIMARÃES, Gustavo Cerqueira. Al Berto, poeta-editor: as margens da poesia. Estudos linguísticos e literários, Instituto de Letras da UFBA, n. 53, jan.-jun. 2015, p. 1-18.

MELO E CASTRO, E. M. Resenha a O medo e Lunário, de Al Berto. Colóquio-Letras, n. 112, Lisboa, novembro/dezembro de 1989, p. 104-5.

PEREIRA, Edgard. Portugal: poetas do fim do milênio. Rio de Janeiro: Ed. Sette Letras, 1999.
PITTA, Eduardo. Al Berto. Metal fundente. Vila Nova de Famalicão: Quase Edições, 2004, p. 11-14.

ASCONCELOS, Maurício Salles. Mundo-Arte: o rastro do novo, o dado do fim. In: VASCONCELOS, Maurício Salles; Coelho, Haydeé Ribeiro (Org.). 1000 rastros rápidos. Belo Horizonte: Autêntica, 1999, p. 204-28.

VENEROSO, Maria do Carmo de Freitas. Perspectiva do Livro de Artista: um relato; Palavras e imagens em livros de artistas. Pós - revista do Programa de Pós-graduação em Artes da UFMG, v. 2 n. 3 mai./2012 p. 10-23: 82-103. 